\title{
A Model to Predict Total Chlorine Residue in the Cooling Seawater of a Power Plant Using Iodine Colorimetric Method
}

\section{Jih-Terng Wang ${ }^{1}$, Ming-Hui Chen ${ }^{2}$, Hung-Jen Lee ${ }^{3}$, Wen-Been Chang ${ }^{2,6,{ }^{*}}$, Chung-Chi Chen ${ }^{4}$, Su-Cheng Pai ${ }^{5}$ and Pei-Jie Meng ${ }^{2,6, *}$}

1 Department of Biotechnology, Tajen University, Pingtung 907, Taiwan

2 National Museum of Marine Biology and Aquarium, Checheng, Pingtung 944, Taiwan

3 Department of Marine Environmental Informatics, National Taiwan Ocean University, Keelung 20224, Taiwan

4 Department of Life Science, National Taiwan Normal University, Taipei 11677, Taiwan

5 Institute of Oceanography, National Taiwan University, Taipei, 107, Taiwan

6 Institute of Marine Biodiversity and Evolution, National Dong Hwa University, Checheng, Pingtung 944, Taiwan

E-Mails: jtw@mail.tajen.edu.tw; minghui@nmmba.gov.tw; wenbeen@nmmba.gov.tw; lecgyver@mail.ntou.edu.tw; ccchen@cc.ntnu.edu.tw; scpai@ccms.ntu.edu.tw; pjmeng@nmmba.gov.tw

* Authors to whom correspondence should be addressed.

Received: 31 January 2008; in revised form: 25 February 2008 / Accepted: 1 April 2008 /

Published: 4 April 2008

\begin{abstract}
A model experiment monitoring the fate of total residue oxidant (TRO) in water at a constant temperature and salinity indicated that it decayed exponentially with time, and with TRO decaying faster in seawater than in distilled water. The reduction of TRO by temperature $\left({ }^{\circ} \mathrm{K}\right)$ was found to fit a curvilinear relationship in distilled water $\left(r^{2}=0.997\right)$ and a linear relationship in seawater $\left(r^{2}=0.996\right)$. Based on the decay rate, flow rate, and the length of cooling water flowing through at a given temperature, the TRO level in the cooling water of a power plant could be estimated using the equation developed in this study. This predictive model would provide a benchmark for power plant operators to adjust the addition of chlorine to levels necessary to control bio-fouling of cooling water intake pipelines, but without irritating ambient marine organisms.
\end{abstract}

Keywords: anti-fouling agent; total residual oxidant; power plant; cooling water. 


\section{Introduction}

Operation of thermal or nuclear power plants located near the seashore requires massive amounts of water for cooling purposes. Inevitably, many sedentary marine organisms, such as barnacles, spirorbis, oysters and bryozoa proliferate on the inner wall of cooling water intake pipelines. The growth of these marine organisms can reduce the rate of thermal exchange, restrict water movement, clog the pipeline, or erode and perforate the wall of the pipeline [1,2]. Under extreme circumstances, power plant operators may have to cease operation to clean and repair the pipeline system. One such case occurred in a thermal power plant of Taipower (the Power Company of Taiwan), where 50 tons of sessile marine organisms had to be removed from the pipeline during a single cleaning process. Many power plants are located near the coasts due to the easy access of seawater for cooling; thus, fouling is a worldwide problem that extends beyond Taiwan.

Many techniques have been developed to inhibit the settlement of sedentary marine organisms [3-8]. Among these techniques, adding chlorine is a widely accepted method to simply and efficiently prohibit fouling. The use of chlorine to avoid fouling occurrence has the supposed benefit of rapid decay of chlorine toxicity. One major drawback of chlorine, however, is that interactions between chlorine and seawater can induce complex chemical reactions that produce compounds with higher toxicity, such as alkyl halides. In seawater, chlorine reacts readily with dissolved bromide, iodine, ammonium ions, among other elements, to produce a series of products such as $\mathrm{Cl}_{2}, \mathrm{HClO}, \mathrm{ClO}^{-}$, $\mathrm{HBrO}, \mathrm{BrO}^{-}$and other halide derivatives. Additionally, previous studies have indicated that bromine ions in the presence of chlorine would be converted to hypobromic acid and hypobromte, and even molecular bromine $[9,10]$. Within these products, more than $99 \%$ was hypobromic acid at $\mathrm{pH} 8.0$. Similarly, the co-existing iodide and iodate in seawater can be converted into hypoiodic acid, hypoiodate, and molecular iodine. Hypobromic acid can also oxidize iodine ions to release bromine ions. Due to the rapid decay of chlorine in seawater, it is unnecessary to use chlorine residue to evaluate its impact to a marine environment. An estimate of the pool of halide derivatives in seawater is a more realistic measure of the potential chlorine impact. Therefore, the American Public Health Association [11] suggested the use of a standard method to determine total residual oxidant (TRO) rather than measuring chlorine residue when dealing with seawater samples.

When chlorine is used as an anti-fouling reagent in a power plant, TRO remaining in discharge seawater is almost inevitable. Contamination of water by TRO can result in adverse effects on fishery activities, which can irritate local fishermen and residents [12-17]. The maximum level of chlorine residue allowed in discharge water in Taiwan is $0.5 \mathrm{mg} / \mathrm{L}$, which is set by Taiwan's Environmental Protection Administration in 2001. However, exceeding this level of chlorine residue is difficult due to high reactivity of chlorine in seawater addressed above. Therefore, there is an increasing importance to establish guidelines for the addition of chlorine to seawater for power plant operators, as well as to produce a more realistic view of the impact of chlorine on the marine environment. Methods for determination of TRO in seawater are found in many references, such as "Standard methods for the examination of water and wastewater" [11]. In this study, we re-evaluate a TRO determination method, iodine colorimetry, with its feasibility on monitoring the TRO level in seawater, and examine the decay of chlorine in seawater at elevated temperatures that would be similar to the 
cooling water from a power plant. The results from this study provide a baseline for the operator of power plant to balance the tradeoff between antifouling requirements and environmental protection.

\section{Results and Discussion}

\subsection{Standard curve and stability of iodine colorimetry}

Absorbance at $325 \mathrm{~nm}$ displayed a strong linear relationship with serial dilutions of a standard TRO solution ( 0 to $5 \mathrm{mg} / \mathrm{L})$, as determined by the iodine colorimetric method $\left(\mathrm{r}^{2}=0.9996\right.$; Fig. 1). Absorbance at 325 increased at a rate of 0.3497 per $1 \mathrm{mg} / \mathrm{ml}$ TRO $(\mathrm{P}<0.0001)$, suggesting that the effectiveness of this method could range from the $\mu \mathrm{g}$ - to mg-level.

Figure 1. The standard curve for the iodine colorimetric determination of TRO. The linear equation of regression curve is $\mathrm{A}_{325}=0.3497$ [conc.] $\left(\mathrm{r}^{2}=0.9996\right)$.

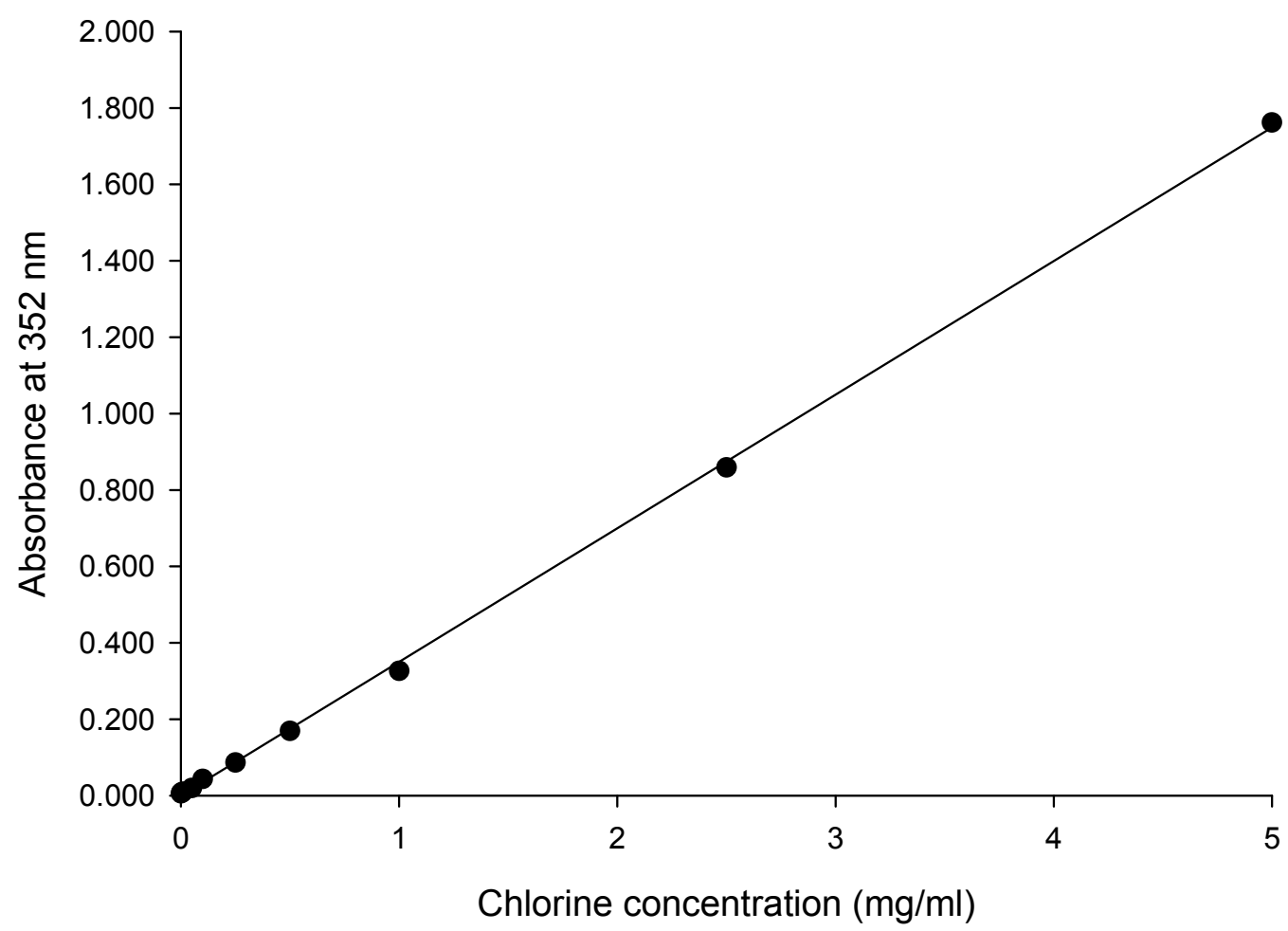

The analytical error of this method was determined with 6 replicates of chlorinated seawater. Consequently, the results indicated that the relative standard deviation was only $0.5 \%$, suggesting the detection of TRO by the iodine colorimetric method was very precise. The detection limit of this method was examined and found to be as low as $4 \mu \mathrm{g} / \mathrm{L}$ TRO. Furthermore, the reaction product determined by iodine colorimetry displayed a nearly stable absorbance within 96 hrs incubation for all concentrations of TRO tested with the exception of the test with $5000 \mu \mathrm{g} / \mathrm{L}$ TRO (Fig. 2). Test with $5000 \mu \mathrm{g} / \mathrm{L}$ TRO displayed a constant decline during incubation, but the reduction in absorbance was less than $10 \%$ before $42 \mathrm{hrs}$ and approximately $21 \%$ at $96 \mathrm{hrs}$. In general, ten percent error is acceptable in many cases when the concentration is greater than the criteria. 
Figure 2. The stability of reaction products when measuring TRO at different concentration by iodine colorimetry. The symbols indicating the concentrations of chlorine added are $\diamond$ for $5,000 \mu \mathrm{g} / \mathrm{L}$; $\square$ for $2,500 \mu \mathrm{g} / \mathrm{L} ; \nabla$ for $1,000 \mu \mathrm{g} / \mathrm{L}$; $\odot$ for $500 \mu \mathrm{g} / \mathrm{L} ; \diamond$ for $250 \mu \mathrm{g} / \mathrm{L} ; \boldsymbol{\Delta}$ for $100 \mu \mathrm{g} / \mathrm{L} ; \boldsymbol{\square}$ for $50 \mu \mathrm{g} / \mathrm{L} ; \bullet$ for $10 \mu \mathrm{g} / \mathrm{L} ; \boldsymbol{\nabla}$ for $0 \mu \mathrm{g} / \mathrm{L}$.

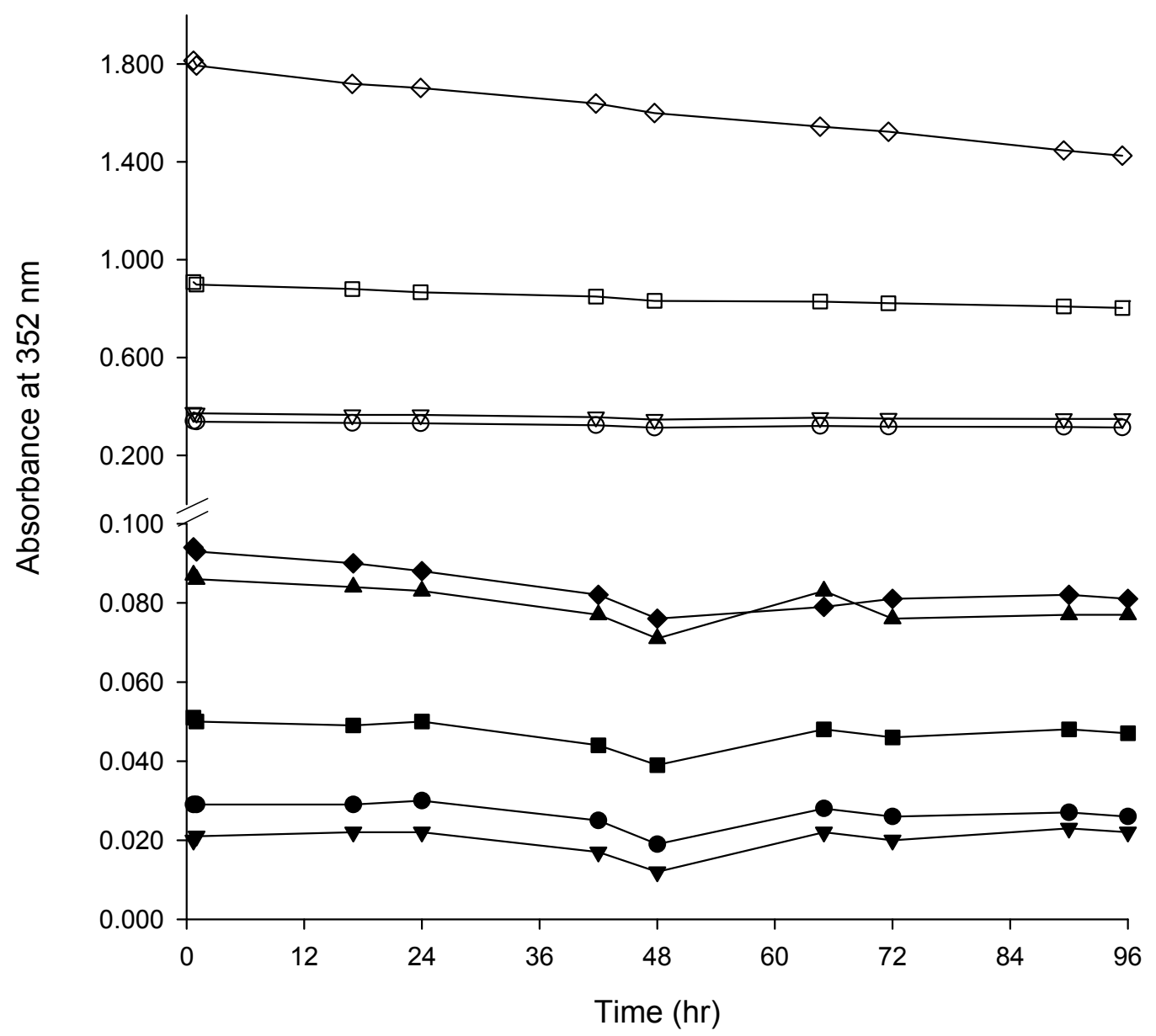

\subsection{Temperature and salinity dependence of TRO determination}

The remaining level of TRO in the water is known to be temperature dependent. When chlorinated seawater flows through a pipeline of a cooling system in a power plant, the remaining chlorine in seawater would be lower than expected due to elevation of seawater temperature. In this study, 4 temperature settings $\left(25,30,40,50^{\circ} \mathrm{C}\right)$ were used to examine the effect of temperature on the availability of TRO in seawater. The effect of salinity was also examined with a parallel trial on examining TRO residue in distilled water. The decays of TRO in distilled water and seawater at different temperature are shown in Fig. 3. In Fig. 3, the decay curve of TRO by time was fit to a nonlinear equation, which explained at least $99.8 \%$ of the total variability in absorbance at $325 \mathrm{~nm}$ for all tests conducted (Table 1). The decay kinetics was comparable to the first order model described by March et al. [18]. 
Figure 3. The decay of TRO in distilled water and seawater at different temperature. (a)-(d) are the decay curves performed in distilled water and (e)-(h) are these performed in seawater at $298^{\circ} \mathrm{K}$ (a and e), $303^{\circ} \mathrm{K}$ (b and f), $313^{\circ} \mathrm{K}$ (c and g), $323^{\circ} \mathrm{K}$ (d and $h$ ).

(a) $\quad \mathrm{y}=0.160 * \exp (-0.0692 x)$
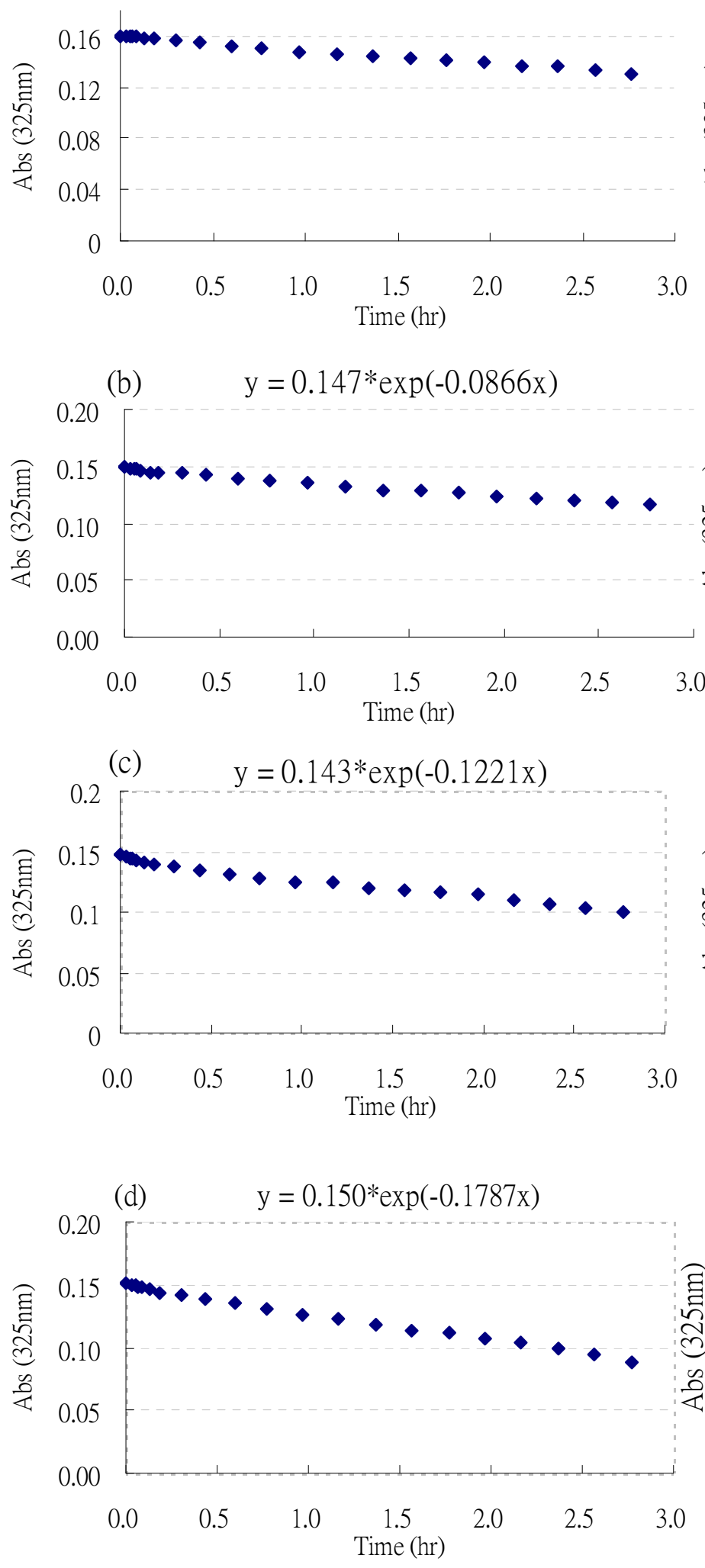

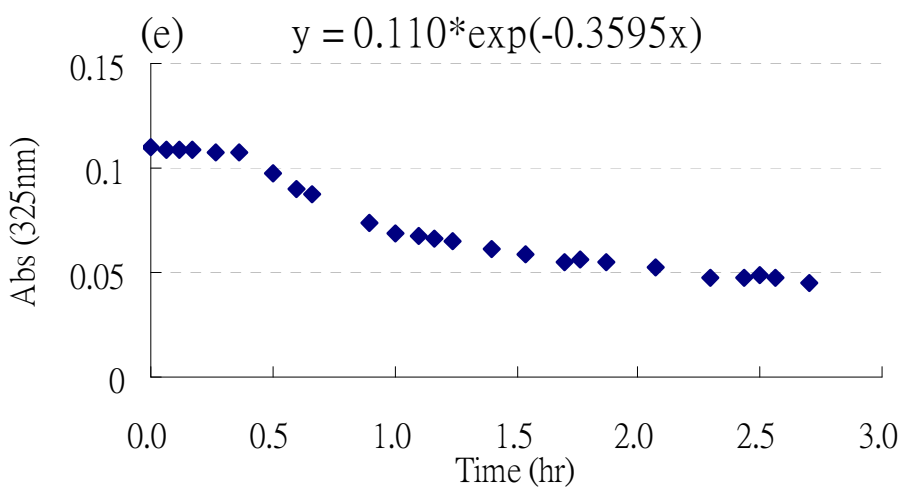

(f) $\quad \mathrm{y}=0.154 * \exp (-0.4262 x)$
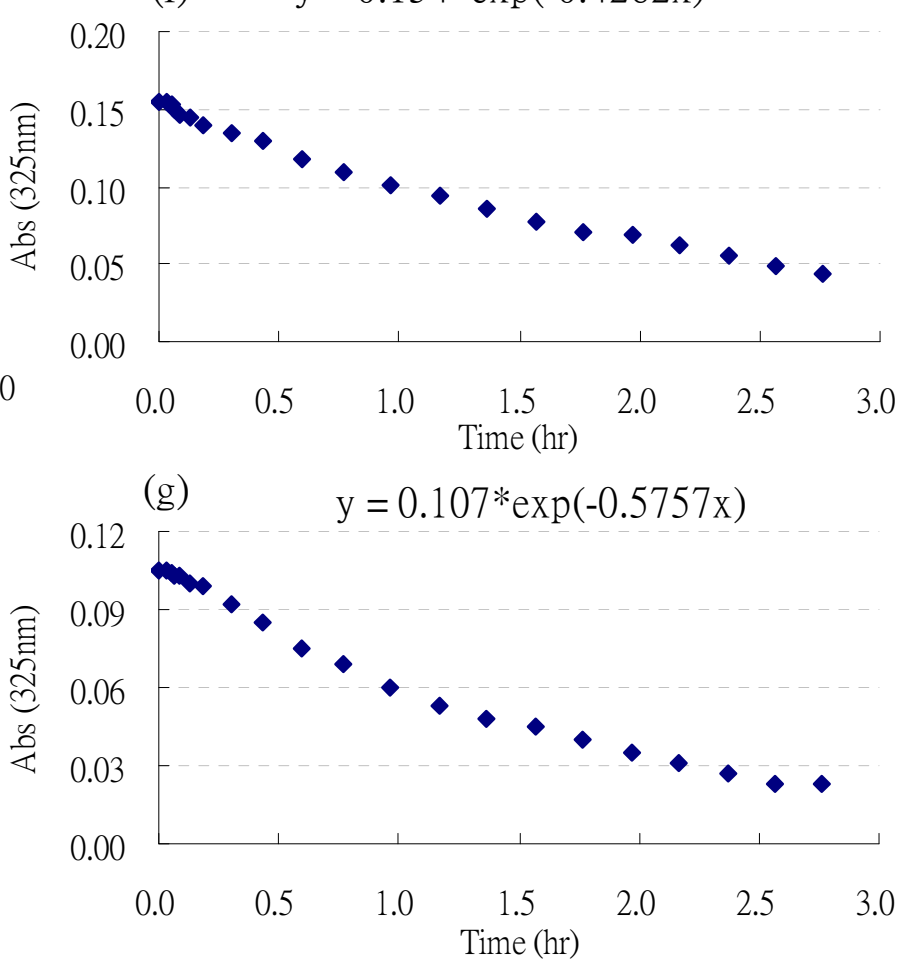

(h) $\quad \mathrm{y}=0.107 * \exp (-0.9043 \mathrm{x})$

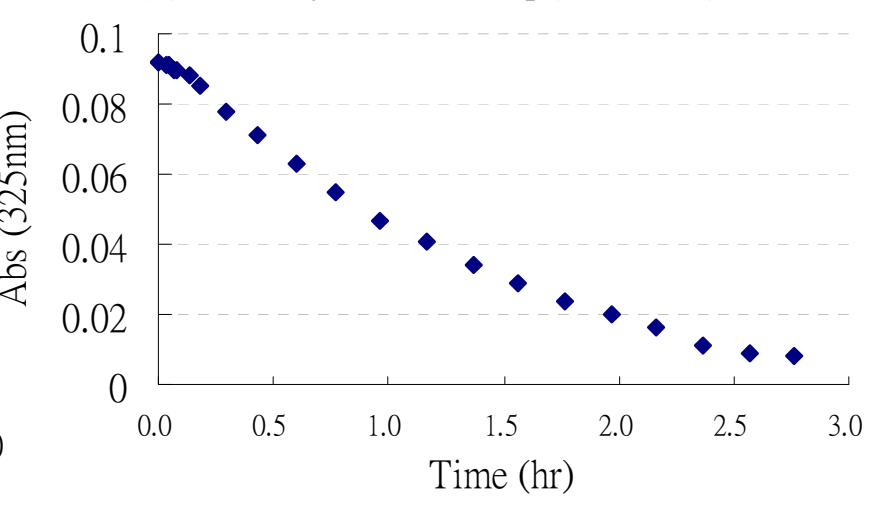


Table 1. The rate of TRO decay in distilled water (DW) and seawater (SW) at a given temperature. The decay of TRO by time was fitted into an equation of $\mathrm{A}_{325}=$ $\mathrm{P} \times e^{(\mathrm{Q} \times \mathrm{t})} . \quad \mathrm{A}_{325}$ is the absorbance at $325 \mathrm{~nm} ; \mathrm{P}$ is the original concentration of added chlorine $(0.9-1.3 \mathrm{mg} / \mathrm{L}$ in this study), $\mathrm{Q}$ is constant, and $\mathrm{t}$ is the incubation time in $\mathrm{hr}$. The half life of TRO in water calculated from above equation is indicated by " $\mathrm{t}_{1 / 2}$ ".

\begin{tabular}{|c|c|c|c|c|c|c|}
\hline \multirow{2}{*}{$\begin{array}{c}\text { Temperature } \\
\left({ }^{\circ} \mathbf{K}\right)\end{array}$} & \multicolumn{3}{|c|}{ DW } & \multicolumn{3}{|c|}{ SW } \\
\hline & $\mathbf{Q}$ & $\mathbf{r}^{2}$ & $\mathbf{t}_{1 / 2}(\mathbf{h r})$ & $\mathbf{Q}$ & $\mathbf{r}^{2}$ & $\mathbf{t}_{1 / 2}(\mathrm{hr})$ \\
\hline 298 & -0.069 & 0.9985 & 10.02 & -0.360 & 0.9993 & 1.93 \\
\hline 303 & -0.087 & 0.9988 & 8.00 & -0.426 & 0.9992 & 1.63 \\
\hline 313 & -0.122 & 0.9981 & 5.68 & -0.576 & 0.9985 & 1.20 \\
\hline 323 & -0.179 & 0.9994 & 3.88 & -0.904 & 0.9985 & 0.77 \\
\hline
\end{tabular}

\subsection{Half life determination of TRO and its application}

The half life of TRO at each temperature can be calculated with this equation. According to the half life $\left(t_{1 / 2}\right)$ of TRO remaining in water (Table 1 ), salinity displayed a strong effect on the loss of available TRO by heating. Among the four temperatures tested, TRO remaining in water ranged from 4.7 to 5.2 times longer in distilled water than in seawater. When the temperature was elevated from $298^{\circ} \mathrm{K}\left(25^{\circ} \mathrm{C}\right)$ to $323^{\circ} \mathrm{K}\left(50^{\circ} \mathrm{C}\right)$, the decrease in the half life of TRO was 2.51 times in seawater and 2.58 times in distilled water. The half life of TRO displayed a strong parabolic relationship with incubation temperature $\left({ }^{\circ} \mathrm{K}\right)$ in distilled water $\left(\mathrm{r}^{2}=0.9967\right.$; Fig. 4) and a linear relationship in seawater $\left(r^{2}=0.9962\right.$; Fig. 4). Temperature has a greater affect on the remaining availability of TRO in distilled water compared to seawater (Figure 4).

2.4 Application of the model

For a power plant located near the sea shore, a predictive method to determine how much chlorine should be added into cooling water to be sufficient for antifouling without introducing a risky amount of TRO in the effluent is needed. According to the standard curve in Fig. 1 and TRO decay rate shown in Table 1, the remaining TRO in the effluent of cooling water can be easily predicted with the equation: $\mathrm{R}=\left[\mathrm{P} \times e^{(\mathrm{Q} \times \mathrm{t})}\right] / 0.3497$ [where $\mathrm{R}$ is the remaining concentration of TRO; $\mathrm{P}$ is originally added concentration of chlorine, $\mathrm{Q}$ is a constant of decay (see in Table 1); and t is the duration time (hr) in the discharging pipeline; 0.3497 is the calibration factor as obtained from standard curve in Fig. 1]. The duration of chlorine remaining in the pipeline and discharging trench could then easily be estimated from flow rate and the length of pipeline. For example, if the added chlorine concentration was $1 \mathrm{mg} / \mathrm{L}$ and the cooling water was delivered at a flow rate of $1 \mathrm{~m} / \mathrm{sec}$ at an average temperature of 
$30^{\circ} \mathrm{C}$, then the remaining TRO concentration in the effluent after running through $1,000 \mathrm{~m}$ cooling process would be $0.28 \mathrm{mg} / \mathrm{L}$.

Figure 4. The relationship between half life of TRO decay and incubation temperature in ${ }^{\circ} \mathrm{K}$. The symbol "•" indicated TRO decay in distilled water and " $\bigcirc$ " in seawater. The regression curve fit by TRO decay in distilled water is $\mathrm{t}_{1 / 2}=0.0051 \mathrm{~T}^{2}-3.4315 \mathrm{~T}+576.07\left(\mathrm{r}^{2}=0.9967\right)$ and that in seawater is $\mathrm{t}_{1 / 2}=-0.0456 \mathrm{~T}+15.4822\left(\mathrm{r}^{2}=0.9962\right)$.

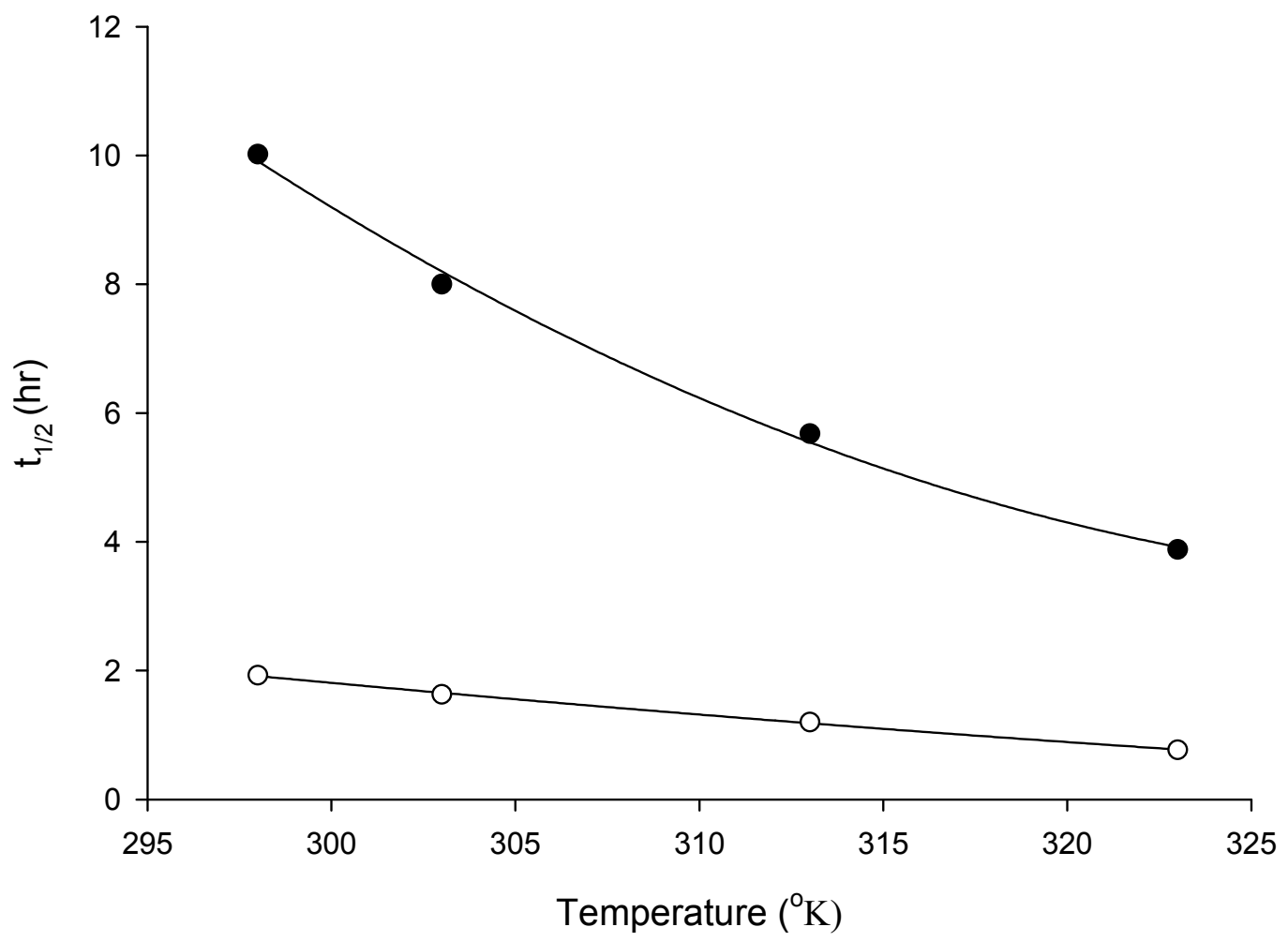

When applying this prediction model, the TOC content in the seawater shall be considered. There were many studies addressed the significant reducing effect of TOC on the chlorine availability $[9,16,17]$. However, in the case of the application in power plant which were always located near the sea environment with good and stable water quality. For example, the characterization of seawater collected from the locations near the inlet of cooling seawater of three nuclear power plants in Taiwan indicated that the $\mathrm{pH}$ were between 8.0 and 8.3, salinity between 33PSU and 35 PSU, and TOC between 0.05 and $1.00 \mathrm{mg} / \mathrm{L}[19,20]$. The water quality used in this model development was also in this range. Table 2 is an example of three power plants in Taiwan which using our prediction model to determine the amounts of chlorine addition and the real measuring data from the water sample collected from the end of discharging pipeline. According to Table 2, the relative errors between predicted value and real determination were practically satisfied, which were mostly below $20 \%$ with few exceptions. Therefore, this prediction model will be feasible for the power plant which could access to the seawater with the similar quality as described above. 
Table 2. Examination of relative error of the model developed in this study. The predicted values of chlorine residue concentration were obtained from the equation $\mathrm{R}$ $=\left[\mathrm{P} \times e^{(\mathrm{Q} \times \mathrm{t})}\right] / 0.3497$. The real chlorine residue concentration at the end of outlet of discharging pipeline was determined by standard water sampling and iodine colorimetry as described in Experimental.

\begin{tabular}{|c|c|c|c|c|}
\hline \multirow[b]{2}{*}{ Power plant } & \multirow[b]{2}{*}{ Date } & \multicolumn{2}{|c|}{ Chlorine residue conc. $(\mathrm{mg} / \mathrm{L})$} & \multirow{2}{*}{$\begin{array}{c}\text { Relative } \\
\text { error (\%) }\end{array}$} \\
\hline & & Predicted value & $\begin{array}{c}\text { Real } \\
\text { determination }\end{array}$ & \\
\hline \multirow{3}{*}{ Second Nuclear Power Plant } & Mar & 0.298 & 0.240 & 21.4 \\
\hline & May & 0.197 & 0.160 & 21.0 \\
\hline & Aug & 0.086 & 0.062 & 32.0 \\
\hline \multirow{3}{*}{ Third Nuclear Power Plant } & Mar & 0.093 & 0.088 & 5.3 \\
\hline & May & 0.081 & 0.070 & 14.7 \\
\hline & Aug & 0.048 & 0.041 & 15.6 \\
\hline \multirow{3}{*}{$\begin{array}{l}\text { Pong-Hu } \\
\text { Plant }\end{array}$} & Mar & 0.140 & 0.133 & 4.8 \\
\hline & May & 0.219 & 0.235 & 7.0 \\
\hline & Aug & 0.069 & 0.046 & 40.2 \\
\hline
\end{tabular}

Furthermore, this predictive model could also be used in the design of cooling systems with the known general conditions (e.g., water temperature $26 \pm 2^{\circ} \mathrm{C}$ and salinity $33 \mathrm{ppt}$ ) and an established median lethal concentration $\left(\mathrm{LC}_{50}\right)$ on local marine organisms. Using these data, this equation could be applied to determine the length of the cooling system for efficiently reducing the hazardous levels of chlorine to safe levels. For example with a data set of $\mathrm{LC}_{50}$ of the marine organisms living around the discharging area of the Third Nuclear Power Plant in Taiwan $[4.5 \mathrm{mg} / \mathrm{L}$ for oyster Crassostrea gigas (length, 73.06 $\pm 12.28 \mathrm{~mm}$ ); $2.2 \mathrm{mg} / \mathrm{L}$ for mussel Mytilus sp. (length, $20.38 \pm 3.27 \mathrm{~mm}$ ); $1.7 \mathrm{mg} / \mathrm{L}$ for barnacle Balanus albicostatus (length, $8.12 \pm 2.16 \mathrm{~mm}$ ); $0.5 \mathrm{mg} / \mathrm{L}$ for Littoraria undulata (length, $16.56 \pm 2.55 \mathrm{~mm}$ ); $0.5 \mathrm{mg} / \mathrm{L}$ for larvae of shrimp Penaeus Vannamei (length, $19.01 \pm 3.82 \mathrm{~mm}$, wet weight $107.1 \pm 118.4 \mathrm{mg}$ ); $4.2 \mathrm{mg} / \mathrm{L}$ for larvae of crab Scylla serrata (length, $9.84 \pm 4.82 \mathrm{~mm}$, wet weight $134.6 \pm 101.3 \mathrm{mg}) ; 0.5$ and $0.3 \mathrm{mg} / \mathrm{L}$ for eggs and fish larvae of grouper Epinephelus malabaraicus ; $0.15 \mathrm{mg} / \mathrm{L}$ for fish larvae of Hypoatherina tsurugae; $0.48 \mathrm{mg} / \mathrm{L}$ for fish larvae of Platax pinnatus (length, $2.65 \pm 0.21 \mathrm{~mm}$, wet weight $0.03 \pm 0.02 \mathrm{mg}$ ); $67 \mathrm{mg} / \mathrm{L}$ for copepod, Apocydops royi (length, $1.03 \pm 0.04 \mathrm{~mm}$ ), and $0.85 \mathrm{mg} / \mathrm{L}$ for Pseudodiaptomus annandaloi, $2.34 \mathrm{mg} / \mathrm{L}$ for Amphipod (length, $4.76 \pm 0.75 \mathrm{~mm}$, wet weight $0.47 \pm 0.21 \mathrm{mg}$ ), $2.9 \mathrm{mg} / \mathrm{L}$ for sea anemone Calliactis sp. (wet weight $142.47 \pm 27.25 \mathrm{mg}$ ), $2.3 \mathrm{mg} / \mathrm{L}$ for hard coral Stylophora pistillata (wet weight $3584.58 \pm 1715.32 \mathrm{mg}$ ), respectively] (unpublished data), we can determine the safety concentration of chlorine allowed to be discharged into this area. If the criteria of TRO discharging into ambient seawater are determined, the optimal chlorine concentration on the basis of TRO measurement in cooling systems and the length of cooling pipeline can be calculated. 


\section{Conclusion}

In this study, we confirmed that the iodine colorimetric method is a feasible approach for determining TRO concentration below $5 \mathrm{mg} / \mathrm{L}$, is extremely precise, and has a stable reaction product for up to $96 \mathrm{hrs}$. Concentration of TRO as high as $5 \mathrm{mg} / \mathrm{L}$ were found to have less than a $10 \%$ reduction in absorbance at $325 \mathrm{~nm}$ within $42 \mathrm{hrs}$ of incubation at room temperature. In comparison to a popular method N,N-diethyl-p-phenylenediamine (DPD) colorimetry, photometric determination of DPD method should be conducted instantly after reaction completed. Thus, the stable reaction product obtained from the iodine method provides a chance for researchers to return samples to the laboratory for further photometric determination after simply spiking samples with an iodine reagent at the time of collection. According to the TRO decay rate (Table 1), the remaining TRO in the effluent of cooling water can be easily predicted. The duration of chlorine remaining in the pipeline and discharging trench could then be easily estimated from flow rate and the length of pipeline. Here in Taiwan, three power plants, The Second Nuclear Power Plant, The Third Power Plant and Pong-Hu Chienshan Power Plant, successfully reduced the amount of chlorine addition by applying the prediction model developed in this study. This predictive equation could also be used in the design of cooling systems when the $\mathrm{LD}_{50}$ of TRO of the marine organisms around the outlet of cooling seawater was obtained.

\section{Experimental}

\section{QA/QC system}

The quality assurance and quality control (QA/QC) system of Taiwan government, set up by Environmental Protection Administration since 1987, was established in our laboratory, which includes a general QA/QC system and high standards of laboratory practices for environmental monitoring. The procedures and frequency used for periodic calibration of the equipment in monitoring must be specific. Calibration practice includes initial calibration, routine calibration, and specific calibration. In general, the Taiwan governmental QA/QC system [21,22] including the sampling techniques, sample handling, laboratory services, glassware and analytical performance (such as control charts), is modified from the systems of USEPA [23], principles of environmental analysis [24] and of QA/QC for analytical laboratory [25].

\section{Iodine colorimetry}

Determination of TRO in seawater was conducted using the method developed by Sugita et al. [26] with some modification. In this study, $1 \mathrm{ml}$ of $0.2 \mathrm{M}$ acetate buffer ( $\mathrm{pH} 4.0$ ) was mixed with $10 \mathrm{ml}$ of the water sample, and then added to $0.4 \mathrm{ml} \mathrm{10 \%} \mathrm{KCl}$ solution. The absorbance at $325 \mathrm{~nm}$ was read with a UV-VIS spectrophotometer (Hitachi model U-2000) after $40 \mathrm{~min}$ of incubation. The iodine colorimetric standard was prepared by dissolving $6.4 \mathrm{~g} \mathrm{KI}$ and $1.2692 \mathrm{~g} \mathrm{I}_{2}$ in $1 \mathrm{~L}$ of milli-Q water (equivalent to $353 \mu \mathrm{g} / \mathrm{ml}$ chlorine) and persevered in a brown bottle. Potassium chloride in the concentration of $3.3 \%$ was used as the seawater blank. 


\section{Stability of iodine colorimetry}

To examine the stability of iodine colorimetry, the reaction solution was prepared with a serial dilution of the iodine colorimetric standard $(10,50,100,250,500,1000,2500,5000 \mu \mathrm{g} / \mathrm{L})$. The serial dilution of iodine colorimetric standards was conducted with distilled water when examining TRO in fresh water system and with $3.3 \% \mathrm{KI}$ in seawater system. The standard solution was mixed with an iodine reagent and then incubated at room temperature from $40 \mathrm{~min}$ to $96 \mathrm{hrs}$ at several time intervals before reading the absorbance at $352 \mathrm{~nm}$.

\section{Determination of temperature-dependent decaying rate}

The decay rate of TRO as a function of temperature was determined using an automated sampling system connected with a UV-VIS spectrophotometer (Hitachi model U-2000; Fig. 5). Temperature was maintained statically in a water bath equipped with a thermal controller (Firstek Scientific-B206) and $\mathrm{pH}$ was determined with a $\mathrm{pH}$ meter (Radiometer Copenhagen-PHM85). To mimic the chlorination of cooling water in a power plant, water samples were first bubbled with an air pump while being mixed with an underwater magnetic stirrer. Then, $3 \mathrm{~L}$ of seawater (TOC content: 0.5-1.0 $\mathrm{mg} / \mathrm{L})$ were heated to a given temperature and chlorinated with $0.1 \mathrm{ml}$ sodium hypochlorite $(0.45 \mathrm{~N})$. After mixing, the chlorinated seawater sample was delivered into the automated sampling system using a peristaltic pump at a rate of 70 r.p.m. The sample was sequentially mixed with acetate buffer in a $90-\mathrm{cm}$ reaction coil and then an iodine reagent in a $120-\mathrm{cm}$ reaction coil. The diameter of the both reaction coils was $1 \mathrm{~mm}$. The absorbance at $352 \mathrm{~nm}$ was monitored with a spectrophotometer in time scan mode. Standard calibration with 5 standard solutions was conducted automatically after each determination.

Figure 5. A diagram of the auto-determination system for monitoring the decay of TRO at a given temperature. The sample, standard, and reagent solution were delivered with three peristaltic pumps (P1, P2, and P3) at the rate of 70 r.p.m. A 7port selection valve was controlled manually to deliver the solution into a reaction coil.

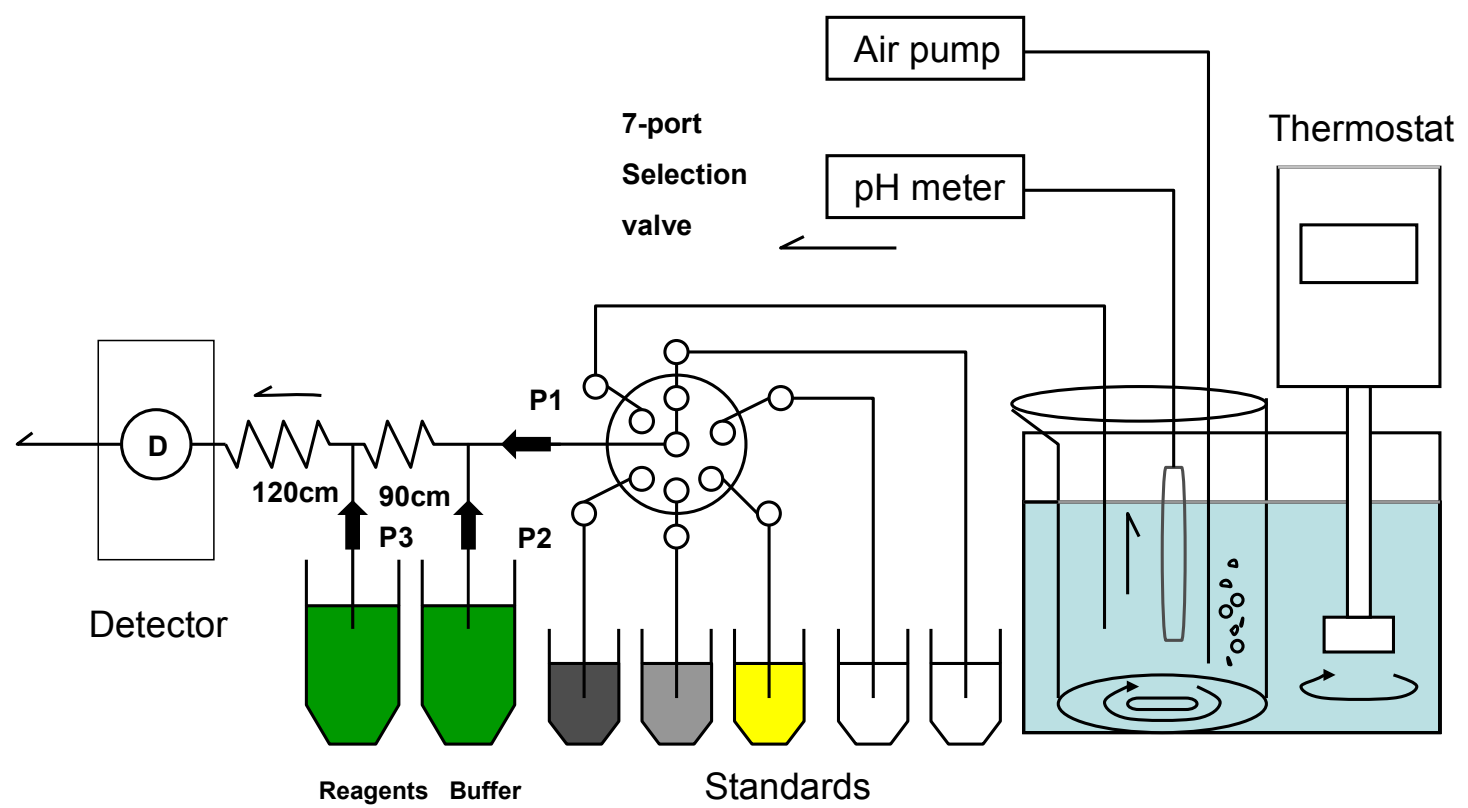




\section{Acknowledgements}

P. J. Meng and W. B. Chang are grateful to Taipower company for financial support of this study.

\section{References}

1. Fisher, S. W.; Stromberg, P.; Bruner, K. A.; Boulet, L. D. Molluscicidal activity of potassium to the zebra mussel Dreissena polymorpha toxicity and mode of action. Aqua. Toxicol. 1991, 20, 219-234.

2. Videla, H. A. Biofilms and corrosion interactions on stainless steel in seawater. Inter. Biodeterioration and Biodegradation 1995, 34, 245-257.

3. Sakaguchi, I.; Shinshima, K.; Kawaratani, K.; Sugai, O. Control of mussel fouling with hot air injection and solid body abrasion (in Japanese); Denryoku Chuo Kenkyusho Hokoku (U89031), 1989; pp.1-51.

4. Rajagopal, S.; Nair, K. V. K.; Azariah, A. Response of brown mussel, Perna indica, to elevated temperatures in relation to power plant biofouling control. J. Therm. Biol. 1995, 20, 461-467.

5. Konstantinou, I. K.; Albanis, T. A. Worldwide occurrence and effects of antifouling paint booster biocides in the aquatic environment: a review. Environ. Inter. 2004, 30, 235-248.

6. Yebra, D. M.; Kiil, S.; Dam-Johansen, K. Antifouling technology-past, present and future steps towards efficient and environmentally friendly antifouling coatings (review). Prog. Org. Coat. 2004, 50, 75-104.

7. Löschau, M.; Krätke, R. Efficacy and toxicity of self-polishing biocide-free antifouling paints. Environ. Pollut. 2005, 138, 260-267.

8. Katranitsas, A.; Castritsi-Catharios, J.; Persoone, G.. The effects of a copper-based antifouling paint on mortality and enzymatic activity of a non-target marine organism. Mar. Pollut. Bull. 2003, 46, 1491-1494.

9. Wong, G. T. F.; Davidson, J. A. The fate of chlorine in seawater. Wat. Res. 1977, 11, 971-978.

10. Wong, G. T. F. Factor affecting the amperometric determination of trace quantitutle of total residual chlorine in seawater. Environ. Sci. Tech. 1982, 16, 785-790.

11. American Public Health Association. Standard Methods for the Examination of Water and Wastewater, $18^{\text {th }}$ Ed.; American Public Health Association: Washington, D.C., USA, 1992.

12. Thatcher, T. O. The relative sensitivity of Pacific Northwest fishes and invertebrates to chlorinated seawater. In Water Chlorination: Environmental Impact and Health Effects; Jolley, R.L., Gorchev, H., Hamilton, D.H., Eds.; Ann Arbor Sci. Publ.: Ann Arbor, MI, USA, 1978; Volume 2, pp. 351360.

13. Dempsey, C. H. The exposure of Herring postlarvae to chlorine in costal power stations. Mar. Environ. Res. 1986, 20, 279-290.

14. Fisher, D. J.; Burton, D. T.; Yonkos, L. T.; Turley, S. D.; Turley, B. S.; Ziegler, G. P.; Zillioux, E. J. Acute and short-term chronic effects of continuous and intermittent chlorination on Mysidopsis bahia and Menidia beryllina. Environ. Toxicol. Chem. 1994, 13, 1525-1534.

15. Fisher, D. J.; Burton, D. T.; Yonkos, L. T.; Turley, S. D.; Ziegler, G. P. The relative acute toxicity of continuous and intermittent exposures of chlorine and bromine to aquatic organisms in the presence and absence of ammonia. Wat. Res. 1999, 33, 760-768. 
16. Allonier, A. S.; Khalanski, M.; Camel, V.; Bermond, A. Characterization of chlorination byproduct in cooling effluents of coastal nuclear power stations. Mar. Pollut. Bull. 1999, 38, 12321241.

17. Nebot, E.; Casanueva, J. F.; Casanueva, T.; Ferná ndez-Bastóm, M. M.; Sales, D. In situ experimental study for the optimization of chlorine dosage in seawater cooling systems. Appl. Therm. Eng. 2006, 26, 1893-1900.

18. March, J. G..; Gual, M.; Ramonell, J. A kinetic model for chlorine consumption in grey water. Desalination 2005, 181, 267-273.

19. Hung, T. C.; Huang, R.; Tan, T. H.; Shao, K. T.; Chen, J. C.; Huang, C. C.; Chu, T. C.; Fun, K. L. An ecological survey on the waters adjacent to the northern Taiwan nuclear power plant sites including Yenliao coastlal area. SCOPE/ROC, Academia Sinica 1998, 103, 524.

20. Su, J.C.; Hung, T.C.; Chiang, Y.M.; Tan, T. H.; Chang, K. H.; Huang, C. C.; Huang, C.Y.; Shao, K. T.; Huang, P. P.; Lee, K. T.; Huang, C. C.; Huang, C. Y.; Fan, K. L.; Yeh, S. Y. An ecological and environmental survey on the waters adjacent to the nuclear power plant in southern Taiwan. SCOPE/ROC, Academia Sinica 1988, 59, 394.

21. Hung, T. C. Quality assurance on environmental analytical chemistry. Journal of Chinese Environmental Protection Society 1987, 10, A1-10.

22. Yang, M.H. Analytical techniques on environmental pollution. National Science Council Monthly 1987, 15, 45-54.

23. USEPA. Handbook for analytical quality control in water and wastewater laboratories EPA-600/479-019. United States Environ. Prot. Agency, 1979.

24. CEI/ACS. Principles of environmental analysis. Committee on Environmental Improvement of American Chemical Society, 1983.

25. AOAC. Quality Assurance Principles for Analytical Laboratories. In Association Office Analytical Chemists, Garfield, F.M., Ed., 1984.

26. Sugita, H.; Hayashi, K.; Asai, T.; Mitsuya, T.; Amanuma, K.; Maruyama, C.; Deguchi, Y. Spectrophotometric method for determination of total residual oxidants in seawater. Suisanzoshoku 1992, 40, 45-49.

(C) 2008 by MDPI (http://www.mdpi.org). Reproduction is permitted for non-commercial purposes. 